\title{
Internet tabanlı harita üretiminde karar destek sistemleri ve coğrafi bilgi sistemi destekli alternatif yaklaşım: müsabaka yöntemi
}

\author{
Melis Uzar' ${ }^{1+}$ (D), Emrah Fatih Asılhan ${ }^{1}$ (D) \\ ${ }^{1}$ Yıldız Teknik Üniversitesi, Davutpaşa Kampüsü, Inşaat Fakültesi, Harita Mühendisliği Bölümü, Esenler, İstanbul.
}

Öz: Gelişen internet ve yapay zekâ teknolojileri ile oluşturulan yeni sistemlerin birbirleri arasında ilişsi kurulması önemli bir ihtiyaç haline gelmiştir. Günümüzde bu sistemlerin kullanılması ile güncel ve doğru bilginin, internet kullanıcıları tarafindan erişilebilir olması sağlanmaktadır. Bu aşamada, Coğrafi Bilgi Sistemi (CBS) veri tabanı ilişkilerini kullanarak analiz ve değerlendirme ile kullanıcılara destek sağlarken, doğru karar verme sürecinde ise Karar Destek Sistemleri (KDS) karar vericilere en ideal sonuçlarl vermektedir. Bu iki sistem incelendiğinde birbirleri ile benzerlikler bulunmasına ră̆men; bu sistemlerin bir arada değerlendirildiği tek bir sistem bulunmamaktadır. Bu durum, kullanıcıların doğru bilgi ve analiz sonuçlarına ulaşmasında problem olmaktadır. Bu çalışmada, yaygıın kullanılan karar verme algoritmalarına alternatif olarak Müsabaka Yöntemi adı altında yeni bir algoritma geliştirilerek; CBS ile KDS'nin bütünleştirilmesi sağlanmıştır. Böylece, önerilen yaklaşım ile karar verme aşamasında ölçütler için anket yapılmasına ve hedef gruplarına gerek kalmadan, elde edilen öznitelik verileriyle güncel ve doğruluğun daha hassas olduğu sonuçlara ulaşılması hedeflenmiştir. Bu çalışmada, İstanbul ilinde yer alan 39 ilçede bulunan nüfus bilgisi, ilçe yüzölçümü, eğitim kurumlart ve ilçelerin sahip olduğu ulaşım ă̆ vb. bilgiler kullanılarak Müsabaka Yöntemi gelişstirilmiştir. Ayrıca, 28 ölçüt baz alınarak ikili karşılaştırmalar yapılmış, avantaj ve dezavantaj durumu analiz edilmiş ve renklendirilmiş puan haritası üretilmiştir. Sonuç olarak, çalışma sonuçlarının internet tabanlı harita ile kullanıcılara hızlı bir şekilde servis edilmesi sağlanmıştır.

Anahtar Sözcükler: Coğrafi bilgi sistemi (CBS), Karar destek sistemleri (KDS), Müsabaka yöntemi, İkili karşılaştırma, İnternet tabanlı harita, Tematik puan haritas1

\section{An alternative approach supported by decision support systems and geographical information system for producing internet based map: competition method}

\begin{abstract}
Establishing relation between new systems, which are created with developing internet and artificial intelligence technologies, has become an important requirement. In today with the use of these systems, the actual and accurate information are provided to be accessible by internet users. In this step, while Geographical Information System (GIS), which uses database relation, supports to the users with analysis and assessment; Decision Support Systems (DSS) give the most ideal results for decision makers in the correct decision making process. Although these two systems are similar when they are examined, there is no available unique system, which assesses them together. This situation has been a problem to get accurate information and analysis results for users. In this study, integration of GIS and DSS has been provided by developing a new algorithm called competition method as an alternative to the other algorithms, which are commonly in use. Therefore, it is aimed with this proposed method to obtain updated and more accurate results by means of attribute data, which are obtained without requiring making surveys and getting target groups for criteria used in the decision process. In this study, the competition method has been developed by using information such as population information, district area, educational institutions, transportation network etc. for 39 districts of Istanbul. In addition, pairwise comparisons were made based on 28 criteria, then advantage and disadvantage status were analyzed and colored score map was produced. As a result; the investigation results have been served to the users quickly with an internet-based map.
\end{abstract}

Keywords: Geographical information system (GIS), Decision support systems (DSS), Competition method, Pairwise comparison, Internetbased map, Thematic score map 


\section{Giriş}

Günümüze kadar yapılmış mekansal bilgi içeren bilimsel çalışmalarda genellikle benzer kurallardan yararlanılarak karar destek sistemi oluşturulmaktadır. Oluşturulan bu sistemler için temelde benzer algoritmalardan yararlanılmakta ya da bu algoritmalardan geliştirilen yeni algoritmalar ile sistem desteklenmektedir. Ancak karar verme aşamasında kullanıcıların tercih edeceği yöntemler bir uygulama bölgesinde birbirine yakın sonuçlar vermekte iken farklı bir uygulama bölgesinde uyumlu olmayan sonuçlar verebilmektedir. Kullanılan yöntemlerde yapılan puanlamalar için anket çalışması ve ankete katılan odak grupları sonuçlara etki etmektedir. Bu durum, karar verme aşamasındaki son kullanıcıya yapacağı tercihin mümkün olduğunca daha objektif nasıl olabileceğinin yollarını aratmaktadır. Ayrıca, son kullanıcı yapacağı çalışmanın önemine göre odak gruplarına ihtiyaç duymadan ya da daha az maliyetli bir karar mekanizmasına zaman zaman ihtiyaç duymaktadır. Bu kapsamda, son kullanıcıların amaç ve isteklerine uygun doğru karar verebilmesi için alternatif daha farklı pratik yöntemlerin de sunulması gereklidir.

Yapılan birçok araştırma alanının çıkış noktası “mekan” olmaktadır (Anbaroğlu, 2017). Mekan bilgilerinin coğrafi bilgiler ile harmanlanmasıyla ortaya çıkan Coğrafi Bilgi Sistemleri (CBS); içinde barındırdığı öznitelik tabloları ile bölge, alan ve yer seçimi belirleme süreçlerinde Karar Destek Sistemleri (KDS) için yardımcı bir araç görevini üstlenmektedir. CBS, kullanıcılara veri tabanı üzerinde sorgu yapılmasına, haritalar üzerinde verilerin düzenlenmesine, mekansal bilgilerin analiz edilmesine ve tüm yapılan işlemlerin sonuçlarının sunulmasına olanak sağlayan araçlardan oluşmaktadır (Taşbaş, Karadağ \& Kösemli, 2015). CBS'nin temel amaçlarından biri de bir bilgi sistemi olmasının yanı sıra mekansal karar verme süreçlerine destek sağlamasıdır (Erden \& Coşkun, 2011). Karar vericiler karar aşamasında oluşturduğu kuralları CBS desteği ile bütünleştirdiği vakit daha anlamlı sonuçlar elde etmektedir. CBS ile KDS bütünleştirilmesi sonucunda Mekansal Karar Destek Sistemleri (MKDS) oluşmaktadır (Malczewski, 1999). Bu çalışmada geçmiş yöntemlerin yanı sıra üretilen algoritmayla yeni bir MKDS metodu geliştirilmiştir. Ayrıca, geliştirilen bu metodun sonuç çıktısı açık kaynak kodlu bir CBS yazılımına aktarılarak renklendirilmiş bir puan haritası üretilmiştir.

\section{Metodoloji}

KDS mühendislikten tıbba; hukuktan bankacılığa kadar hemen hemen birçok alanda kullanılmaktadır. Çoğu zaman doğru sonuçlar elde etmeyi hedefleyen KDS, büyük ölçüde modellemelere dayanmaktadır (Laudon, K. C. \& Laudon J. P., 2006). Bu konuda literatürde yapılan KDS çalışmalarında kullanılan yöntemler ve bu alanda yapılan çalışmalar çoğunlukla benzerlik göstermektedir. Santos, Coutinho-Rodrigues ve Antunes (2011)'deki çalışmada belirledikleri ölçütler ile ulaşım araçları için Google haritalarla bütünleştirmeli bir mekansal web tabanlı karar destek sistemi geliştirmişlerdir. Coutinho-Rodrigues, Simão ve Antunes (2011)'de kentsel planlama alt yapısı için TOPSIS (Technique for Order Preference by Similarity to Ideal Solution) ve ELECTRE (Elimination Et Choix Traduisant la Realite) yöntemini kullanarak CBS tabanlı çok ölçütlü karar destek sistemi yapmışlardır. Uyan, Çay ve Akçakaya (2013) arazi toplulaştırması için bir ara yüz geliştirerek SQL (Structured Query Language) sorgularıyla tahsis için en uygun parselin belirlenmesi adına KDS geliştirme çalışması gerçekleştirmişlerdir. Yao, Zhu, Yun, Peng ve Li (2017)'de Çin'de ağ üzerinde geliştirdikleri veri tabanlarıyla çekirge sürülerinin zararlarını önlemeye yönelik bir KDS kullanmışlardır. İrfan, Koj, Sedighi ve Thomas (2017)'de KDS için kullanılan AHP (Analytic Hierarchy Process) yöntemi ve SOM (Self-organizing map) yer seçim metodu gibi yöntemleri birleştirerek bir KDS çalışması gerçekleştirmişlerdir. Yapılan birçok çalışma birbirlerini tamamlar nitelikte olup hassas sonuçlar vermektedir. Fakat her ne kadar hassas sonuçlar alınmış olsa da daha kesin sonuçlara ulaşabilmek için farklı yöntemlerin ve fikirlerin geliştirilmesi; üretilen yeni metotların test edilmesi gerekmektedir. Ayrıca yapılan çalışmalar; araştırma, planlama ve uygulama aşamalarında karar vericilere hizmet ederek katkı sağlamalıdır. Böylece ihtiyaç duyulan 
bilgilere hızlı ve zamanında erişim sağlanarak alınan kararların kalitesi yükselecektir (Arslan \& Y1lmaz, 2010).

Karar analizi, karmaşık karar problemlerinin matematiksel modelini tasarlayarak, sistematik işlemler ve istatistiksel irdelemelerle çözümlenmesi olarak tanımlanmaktadır. Kullanıcılar, problem çözme ve karar verme aşamasında elinde mevcut olan bilgiler ile işlem yapmaktadır. Bilgiler yumuşak ve sert bilgi olmak üzere iki türden oluşmaktadır. Sert bilgi nicel ve nitel verilerle temsil edilirken; yumuşak bilgiler karar vericilerin tercihleri, öncelikleri ve kararlarından oluşmaktadır (Aydın \& Erdoğan, 2011). Karar verme aşamasında ise kullanıcılar çeşitli yöntemler kullanmaktadır. Bu yöntemlerden biri olan ELECTRE; karar seçeneklerinin ölçütleri arasında kurulan ağırlık matrisleri ilişkisine dayanmaktadır. Bu yöntemin uygulamasında karar vericiler tercihlerine uygun ağırlık değerlerini belirlemektedir. Belirli ölçütler ve her seçenek için bu ölçütlerin ağırlık değerleri mevcut ise yöntemin kullanılması uygundur (Karacasu, 2007). Diğer bir yöntem olan TOPSIS ise; alternatif ve ölçütler arasından oluşan evrensel kümede çözüm alternatiflerini pozitif ideal çözüm noktasına en kısa mesafe ve pozitif ideal çözüm noktasına en uzak mesafede olabileceği varsayımına dayanmaktadır (Demireli, 2010). Çok ölçütlü karar verme mekanizmalarında sıkça kullanılan AHP'de seçim işlemleri, karar verme aşamasında önceden belirlenen ölçüt puanlamasına göre yapılmakta ve sonuca odak grupları etki etmektedir. AHP'de karar süreçleri arasındaki ilişki tek yönlüdür (Ömürbek \& Şimşek, 2014). AHP, ELECTRE ve TOPSIS yöntemleri incelendiğinde; bu üç yöntemde kullanıcıların karar noktası için belirlemiş oldukları değerlendirme faktörleri arasında ilişki kurabilmek için çeşitli matematiksel işlemler yapması gerekmektedir. Yapılan işlemlerde uyumsuz ilişkilerin ortaya çıkması yapılan işlem sayısının artmasına sebep olduğu kadar verilerin doğru değerlendirilememesine de neden olmaktadır. Artan işlem adımları kullanıcının sonuca ulaşmasını geciktirmektedir. Ayrıca çıkan sonuçlarda oransal olarak birbirine yakın küsuratlı sonuçlar çıkması kullanıcıyı tekrardan değerleme yapabileceği başka pratik çözüm yollarına yöneltmektedir. Bu kapsamda, karar vericilere oransal olarak birbirine yakın sonuç vermeden ve belirlenen ölçütlere göre ikili karşılaştırmaların yapıldığı Müsabaka Yöntemi geliştirilmişstir. Önerilen bu yöntem ile; ölçütlere ve alternatiflere dişarıdan müdahale edilmeden, tüm alternatiflerin, kendi sahip olduğu öz sayısal değerler üzerinden ikili karşılaştırmalar yapılarak, değerlendirilme faktörlerine puan verilmektedir. Ayrıca bu faktörler, toplanan puan sonucunda sıralanmaktadır. Önerilen yaklaşımla uygulanan ikili karşılaştırma algoritması, alternatiflerin kendi içerisinde bağımsız iken, tüm alternatiflere ise birbirlerine karşı bağımlı olarak değerlendirilmesine olanak sağlamaktadır.

\section{Sayısal Uygulama}

\section{1 Çalışma Alanı ve Kullanılan Veriler}

Bu çalışmada, pilot bölge olarak İstanbul ili seçilmiştir (Şekil 1). İstanbul ili Türkiye’nin en kalabalık ili olup; 39 ilçesi bulunmaktadır. Ayrıca, nüfus yoğunluğundan dolayı kamu ve özel kurumların bu bölgede çok olması, bu bölgeye olan yatırım projesi gerçekleştirme talebinin her geçen gün artması gibi unsurlar çalışma alanında bu bölgenin seçilmesinin önemli sebeplerinden biridir.

Uygulamada, ilçelere ait demografi, ulaşım, sağlık, alışveriş, eğitim gibi bilgiler için resmi kaynaklardan temin edilen verilerden yararlanılmıştır. Demografi kategorisi: nüfus, yüzölçümü ve nüfus yoğunluğundan; sağlık kategorisi: devlet hastaneleri, özel hastaneler ve üniversite hastanelerinden; ulaşım kategorisi: raylı sistemler, şehir içi otobüs, Türkiye Cumhuriyet Devlet Demir Yolları (TCDD), şehirlerarası otobüs terminali (otogar), hava limanı, gar ve deniz otobüsünden oluşmaktadır. Bu verilere ek olarak alışveriş kategorisi için; alışveriş merkezlerinden (AVM) ve eğitim kategorisi için: kütüphane, Halk Eğitim Merkezi ve Akşam Sanat Okulu (HEM ve ASO), Milli Eğitim Bakanlığı'na (MEB) bağlı ortaöğretim kurumları, Yükseköğretim Kurumu'na (YÖK) bağlı üniversiteler ve MEB'e bağlı özel yurtlardan oluşan veriler elde edilmiştir. Önerilen yöntemin geliştirilmesi sırasında internet ortamında kamuya açık ve resmi kaynaklarca yayımlanmış olan 
güncel bilgiler kullanılmıştır. Çalışmada kullanılan veriler ve temin edildiği kanallar Tablo 1'de detaylı bir şekilde verilmiştir.

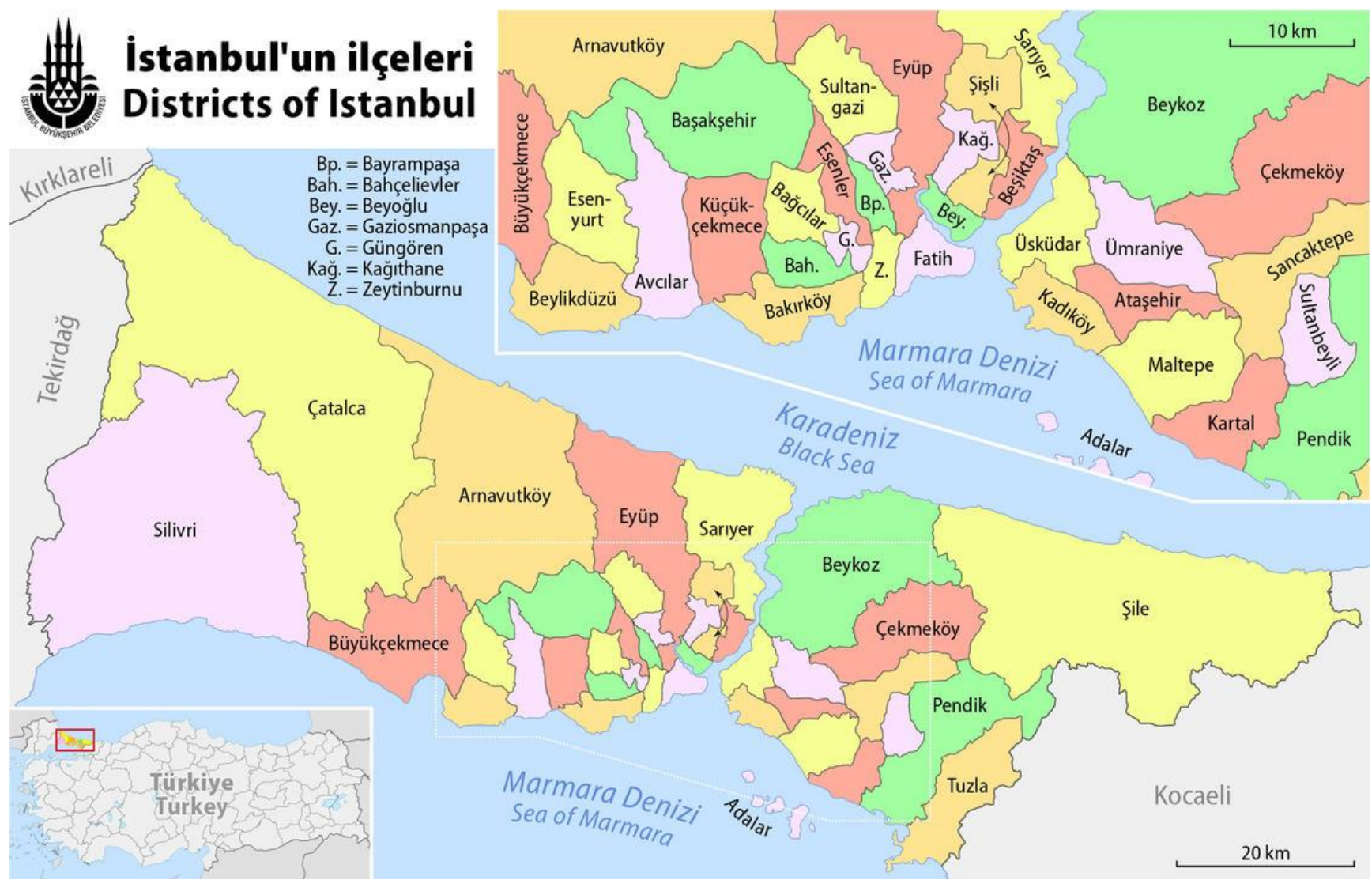

Şekil 1: Çalışma alanı (URL-1)

Tablo 1: Kullanılan veriler

\begin{tabular}{lll}
\hline Kategori & Veri Adı & Veri Kaynă̆ı \\
\hline \multirow{3}{*}{ Demografi } & İçe Nüfusları & \\
& İçe Yüzölçümleri & http://www.tuik.gov.tr/ \\
& İçe Nüfus Yoğunluğu & \\
\hline \multirow{3}{*}{ Sağlık } & Devlet Hastanesi & http://www.istanbulsaglik.gov.tr/index,asp \\
& Özel Hastane & \\
\hline \multirow{5}{*}{ Üniversite Hastanesi } & Şehir Hatları (Vapur, Motor) & http://www.sehirhatlari.istanbul \\
& Raylı Sistemler (Metro, Tramvay) & https://www.metro.istanbul/ \\
& Otobüs (İETT, Otobüs A.Ş. ÖHO) & https://www.iett.istanbul/ \\
& TCDD (Marmaray) & http://www.marmaray.gov.tr/ \\
& Deniz Otobüsü & https://budo.burulas.com.tr/ https://www.ido.com.tr/ \\
& Terminal, Havalimanı, Gar & https://yandex.com.tr/harita/ \\
\hline \multirow{4}{*}{ Alışverişs } & AVM & http://earsiv.gov.tr/Kutuphane-Listesi.aspx \\
& Kütüphane & http://www.meb.gov.tr/ \\
& Oalk Eğitim Merkezi \& Akşam Sanat & http://www.meb.gov.tr/ \\
& Ortaöğretim Kurumları & https://www.yok.gov.tr/universiteler/universitelerimiz \\
& Üniversiteler & http://ookgm.meb.gov.tr \\
\hline
\end{tabular}

\section{2 Çalışma Alanı ve Kullanılan Veriler}

KDS önceden belirlenen ölçütlere göre; çevresel ve sosyo-ekonomik göstergelere karşı önerilen, planlama müdahalelerini değerlendiren ilkelere dayanmaktadır (Gonzàlez, Donnelly, Jones, Chrysoulakis \& Lopes, 2013). KDS uygulamalarında çalışmanın sonucunu etkileyen kıstaslardan birisi de güncel veridir. Bu çalışmada, KDS için resmi kurumların internet 
sayfalarında yer alan güncel verilerden yararlanılmıştır. İlk adımda, elde edilen veriler ortak bir havuzda toplanmış ve havuzda toplanan verilerden ölçütlerine göre uygun sınıflar oluşturulmuştur. Bir sonraki adımda, karşılaştırma yapılacak ilçe takımları belirlenmiş, takımlar oluşturulan müsabaka fikstürüne göre ikili karşılaştırılmıştır. Müsabaka sonuçları, sonuç tablosuna işlenerek puan cetveli oluşturulmuştur. Son adımda ise puan cetvelinde yer alan ilçeler, çok puandan az puana doğru, eşit puanlı ilçeler ise aralarında yapılan ikili karşılaştırma sonucu yüksek puandan düşük puana göre sıralanmıştır. Müsabaka Yöntemi'nin uygulama işlem adımları Şekil 2'de verilmiştir.

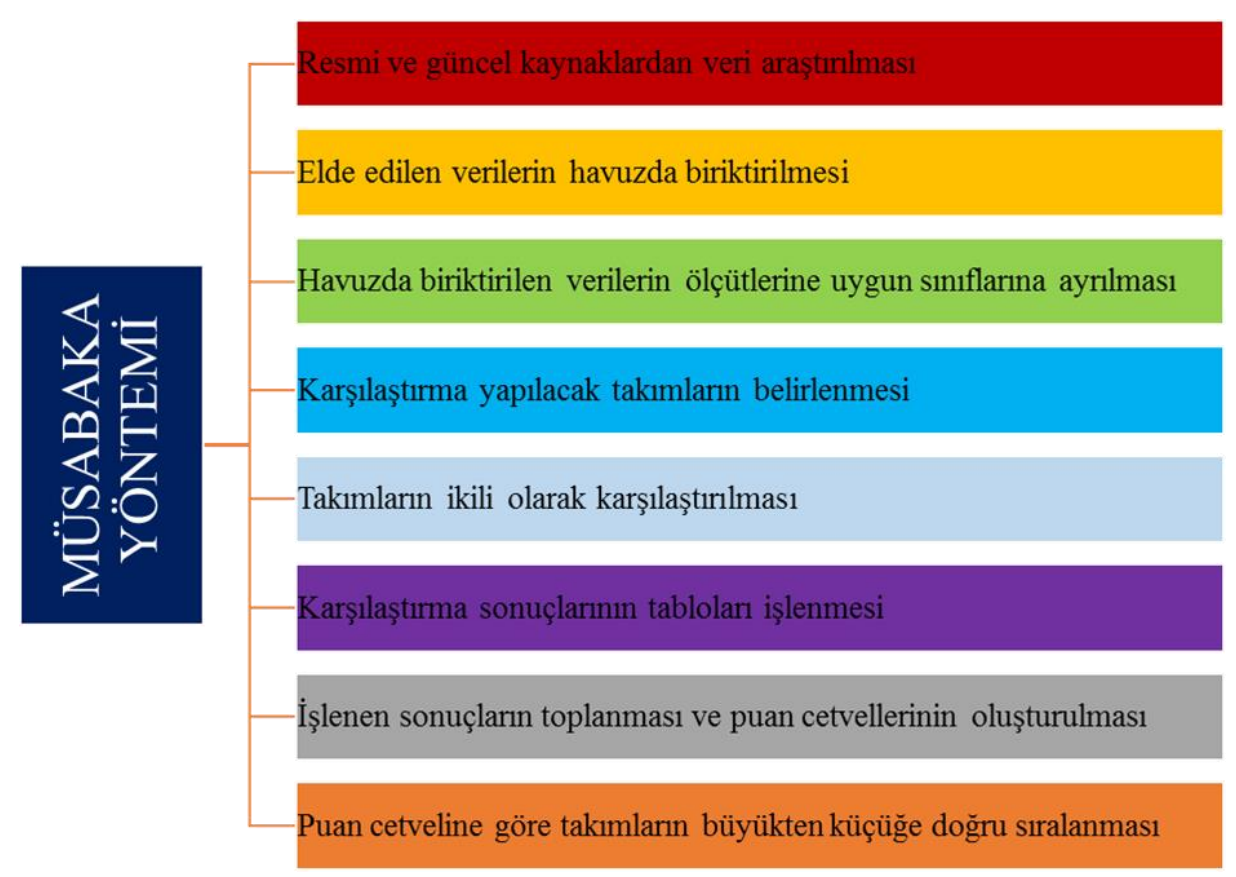

Şekil 2: Müsabaka yöntemi işlem adımları

Müsabaka Yöntemi’nde, uygulamada kullanılan her bilgi “spreadsheet” adı verilen elektronik excel tablolarında işlenerek excel komutları yardımıyla, çalışma bölgesinde yer alan 39 ilçe arasında bağlantı sağlanmıştır. Elektronik tabloların kullanılmasındaki amaçlardan biri; son kullanıcıların hem kendi mantığına göre elektronik tablolara müdahale etmesine yardımcı olmak, hem de ücretli yazılımların yanı sıra mevcut imkânlar kullanılarak ücretsiz bir şekilde bu işlemlerin yapılabilmesine olanak sağlamaktır. Ayrıca, elektronik tablolar programcıların, programlama görevlerini basitleştirerek veya otomatikleştirerek uygulamalar geliştirmesine yardımcı olan bir yazılım aracı olarak düşünülebilir (Grossman, Mehrotra \& Özlük, 2007). Çalışmada, elektronik tablolardan yararlanılarak veri tablosu, genel fikstür tablosu, müsabaka tablosu ve puan sıralı ilçe tablosu tasarlanmıştır. Bu veri tablosuna 39 ilçe 28 farklı ölçütte, ilçelerin sahip olduğu veri sayısı eklenmiştir. Daha sonra ilçeler ikili karşılaştırmaların yapıldı ̆̆ı genel fikstür tablosuna "EĞERSAY", "TOPLA” ve "EĞER” vb. temel excel fonksiyonlarıyla kodlama yapılarak tablolar arası bağlantı yapılmıştır. Bu bağlantı ile her ölçütün aralarında sadece bir kez karşılaştırılması koşulu ile tabloda diziliş sırası gözetmeksizin 741 adet ikili karşılaştırma yapılarak karşılaştırma sonuçları elde edilmiştir. Elde edilen sonuçlar karşılaşma sayısı (KS), galibiyet (G), beraberlik (B), mağlubiyet (M), alınan sayı (AS), verilen sayı (VS), averaj (AV) ve puan (P) bilgisinin bulunduğu müsabaka tablosuna yazdırılmış ve bu doğrultuda sonuçlar elde edilmiştir. Ölçütler arasında kurulan ilişsilerden elde edilen sonuçlara uygun sıralı ilçe puan tablosu oluşturularak tablolar doldurulmuştur. Kurgulanan tablo örneği Şekil 3’te, gerçekleştirilen tüm işlemlerin her ölçütü için uygulanan algoritma yapısı Şekil 4'te yer almaktadır. Bu yapıya ilişkin sözde kod örneği ise Şekil 5'te verilmiştir. 


\begin{tabular}{|l|c|l|l|l|l|l|}
\hline iLÇELER & $\begin{array}{c}\text { ilçe } \\
\text { Nüfusu }\end{array}$ & Yüzölçüm & Yoğunluk & Devlet & Özel & ÜniHast \\
\hline ADALAR & & & & & & \\
\hline ARNAVUTKÖY & & & & & & \\
\hline ATAŞEHiR & & & & & & \\
\hline AVCILAR & & & & & & \\
\hline BAĞCILAR & & & & & & \\
\hline BAHÇELIEVLER & & & & & & \\
\hline BAKIRKÖY & & & & & & \\
\hline BAŞAKŞEHIR & & & & & & \\
\hline BAYRAMPAŞA & & & & & & \\
\hline BEŞiKTAŞ & & & & & & \\
\hline
\end{tabular}

(a)

\begin{tabular}{|l|c|c|c|c|c|c|}
\hline \multirow{2}{*}{ FIKSTÜR } & ADALAR & ARNAVUTKÖY & ATAŞEHIR & AVCILAR & BAĞCILAR \\
\cline { 3 - 7 } & 1 & 2 & 3 & 4 & 5 \\
\hline ADALAR & 1 & $*$ & & & & \\
\hline ARNAVUTKÖY & 2 & & $*$ & & & \\
\hline ATAŞEHIR & 3 & & & $*$ & & \\
\hline AVCILAR & 4 & & & & $*$ & \\
\hline BAĞCILAR & 5 & & & & & $*$ \\
\hline
\end{tabular}

(c)

\begin{tabular}{|l|l|l|}
\hline \multicolumn{3}{|c|}{ ADALAR } \\
\hline ADALAR & & ARNAVUTKÖY \\
\hline ADALAR & & ATAŞEHIR \\
\hline ADALAR & & AVCILAR \\
\hline ADALAR & & BAĞCILAR \\
\hline ADALAR & & BAHÇELLEVLER \\
\hline ADALAR & & BAKIRKÖY \\
\hline ADALAR & & BAŞAKŞEHIR \\
\hline ADALAR & & BAYRAMPAŞA \\
\hline ADALAR & & BEŞIKTAŞ \\
\hline ADALAR & & BEYKOZ \\
\hline
\end{tabular}

(b)

\begin{tabular}{|l|l|l|l|l|l|l|l|l|}
\hline TAKIMLAR & KS & G & B & M & AS & YS & AV & P \\
\hline ADALAR & & & & & & & & \\
\hline ARNAVUTKÖY & & & & & & & & \\
\hline ATAŞEHIR & & & & & & & & \\
\hline AVCILAR & & & & & & & & \\
\hline BAĞCILAR & & & & & & & & \\
\hline BAHÇELIEVLER & & & & & & & & \\
\hline
\end{tabular}

(d)

Şekil 3: Tablo örnekleri (a) veri tablosu, (b) genel fikstür tablosu, (c) müsabaka tablosu, (d) puan sıralı ilçe tablosu

Önerilen Müsabaka Yöntemi puanlama algoritmasına göre; veriler derlenip ilçeler arasında bağlantı kurulduktan sonra ilk adımda ilçelerle birlikte seçenek ve ölçüt tabloları oluşturulmuştur. Daha sonra bu tabloda bulunan her ilçe için ikili karşılaşma ile bir müsabaka programı hazırlanmıştır. Hazırlanan müsabakalarla 39 ilçe için kendi aralarında tüm ölçütler için evet/hayır mantığına dayanarak bir seçim ölçütü uygulanmıştır. Bu adımda; olumlu durum ölçütü için 3 puan, eşit durumlu ölçütler için 2 puan, olumsuz durum ölçütü için de ilçelere 1 puan verilmiştir. Bu ölçütlere göre 3-1, 2-2 veya 1-3 gibi her bir ölçüt için devre veya setlere benzer sonuçlar bulunmuştur. Şekil 6'da takımların sahip olduğu ölçüt verileri ve bu ölçütler arasından yapılan karşılaştırma sonuçlarının örnek gösterimi yer almaktadır.

Belirlenen ölçütlere uygun olarak tüm takımlar tablolar arasından ikili olarak tek tek karşlaştırılmıştır (Şekil 6). Kurulan algoritmadan elde edilen sonuçlara göre; Fatih ilçesi 39 ilçe içerisinde yapılan 38 karşılaşma içerisinden toplamda 36 defa üstünlük sağlayarak 3 puan, 1 kere diğer ilçeyle eşitliği bozmayarak 2 puan ve 1 kere de diğer ilçe kıyaslamasında az puan aldığı için 1 puan alarak toplamda 111 puan toplamıştır. Fatih ilçesine benzer şekilde Kadıköy ilçesi de ikili karşılaştırmalar sonucu 111 puan topladığı gözlenmiştir. Ancak, Fatih ilçesi genel averajda Kadıköy ilçesinden daha yüksek averaj puanına sahiptir. Bu durumda, Fatih ilçesi averaj puan avantajıyla Müsabaka Yöntemi ile en çok puan alarak 39 ilçe arasında verilen 28 ölçüte göre en optimum ilçe olarak seçilmiş ve karar vericiye önerilebilecek en uygun ilçe olmuştur. Elde edilen bu sonuçlarla, her bir ilçe için ayrı ayrı toplanarak müsabaka sonuçları belirlenmiş; belirlenen sonuçlar ilçe lig tablosuna aktarılmıştır. Elde edilen sonuçlara göre 39 ilçe ilk durumda en çok puan alandan en düşük puan alan ilçeye doğru sıralanmış; ikinci durumda ise eşit puanlı ilçeler kendi arasında genel averaj durumu baz alınarak iç sıralama yapılmıştır. Oluşan sıralamaya göre karşılaştırma puan tablosu güncellenerek son şeklini almıştır. Şekil 7'de elde edilen sıralama tablosunun ilk ve son durumu gösterilmektedir. 


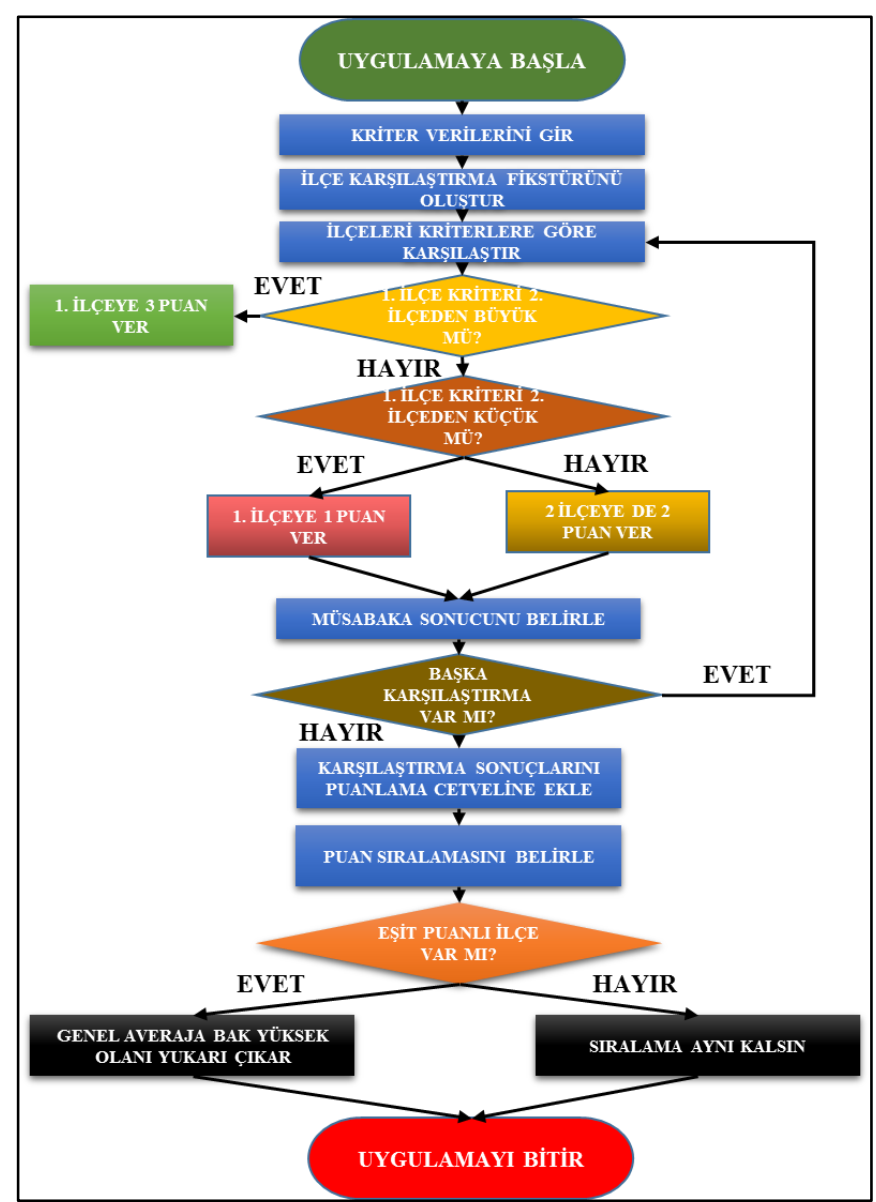

Şekil 4: Müsabaka yöntemi puanlama algoritma yapısı

\begin{tabular}{|c|c|}
\hline (1) begin & \\
\hline (2) & input Elektronik tablolara veri girişi yap; \\
\hline (3) & Müsabaka fikstürünü oluştur; \\
\hline (4) & set $\mathrm{a}=$ 'birinci ilçe'; b='ikinci ilçe'; $\mathrm{k1}$ = 'birinci ilçe ölçüt'; $\mathrm{k} 2=$ 'ikinci ilçe ölçüt'; \\
\hline (5) & if $\mathrm{k} 1>\mathrm{k} 2$; "a'ya 3 puan ekle" and "b'ye 1 puan ekle"; \\
\hline (6) & elseif $\mathrm{k} 1$ = k2; "a'ya 2 puan ekle" and "b'ye 2 puan ekle"; \\
\hline (7) & else "a'ya 1 puan ekle" and "b'ye 3 puan ekle"; \\
\hline (8) & end; \\
\hline (9) & Karşılașma sonuçlarını topla, ilçeleri puanlara göre sırala; \\
\hline$(10)$ & set $\mathrm{p} 1$ = 'birinci ilçe genel puan'; $\mathrm{p} 2$ = 'ikinci ilçe genel puan'; \\
\hline$(11)$ & a1='birinci ilçe toplam averaj'; a2='ikinci ilçe toplam averaj'; \\
\hline$(12)$ & if $\quad \mathrm{p} 1>\mathrm{p} 2$; "siralama ayn kalsin"; \\
\hline (13) & else $\mathrm{p} 1=\mathrm{p} 2$ \\
\hline (14) & if $\quad$ a1 $>$ a2; "siralama aynı kalsın"; \\
\hline$(15)$ & else sıralamada a ile b'yi yer değiștir"; \\
\hline$(16)$ & end; \\
\hline$(17)$ & end; \\
\hline (18) & end; \\
\hline
\end{tabular}




\begin{tabular}{|c|c|c|c|c|c|c|c|c|c|c|c|c|c|c|c|c|c|c|c|c|c|c|c|c|c|c|c|c|}
\hline ilçeler & \begin{tabular}{|c|} 
ilçe \\
Nüfusu
\end{tabular} & Yüzölçüm & Yoğunluk & Devlet & Özel & ÜniHast & $\mid$\begin{tabular}{c|} 
Şehir \\
Hatları
\end{tabular} & \begin{tabular}{|c|} 
Rayli \\
Sistemler
\end{tabular} & Otobüs & Marmaray & Terminal & $\left|\begin{array}{c|}\text { Hava } \\
\text { Limanı }\end{array}\right|$ & Gar & $\left|\begin{array}{c|}\text { Deniz } \\
\text { Otobüsüü }\end{array}\right|$ & AVM & Kütüphane & Hem_ASO & AiHL & AL & ÇPAL & $\mathrm{FL}$ & MTAL & $S B L$ & Devlet & Özel & Fakülte & MYO & Yurt \\
\hline ADALAR & 14.478 & 15.85 & $\% 0,10$ & 1 & 0 & 0 & 4 & 0 & 0 & 0 & 0 & 0 & 0 & 0 & 0 & 2 & 3 & 34 & 102 & 306 & 0 & 0 & 0 & 0 & 0 & 0 & 0 & 0 \\
\hline ARNAVUTKÖY & 247.507 & 6.52 & 1,67 & 1 & 1 & 0 & 0 & 0 & VAR & 0 & 0 & 0 & 0 & 0 & 0 & 0 & 5 & 612 & 748 & 374 & 0 & 1598 & 0 & 0 & 0 & 0 & 0 & 2 \\
\hline ATAŞEHiR & 2.513 & 5.84 & 2,85 & 2 & 6 & 2 & 0 & 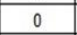 & VAR & 0 & 1 & 0 & 0 & 0 & 4 & & 8 & 680 & 1326 & 238 & 0 & 2144 & 0 & 0 & 2 & 2 & 1 & 14 \\
\hline AVCILAR & 0.770 & .23 & 91 & 2 & 3 & c & 0 & 0 & $A R$ & 0 & & 0 & 0 & 1 & 1 & & 4 & 374 & 918 & 272 & 0 & \begin{tabular}{|l|}
2246 \\
\end{tabular} & 0 & 0 & 4 & 3 & 1 & 32 \\
\hline BAĞCILAR & 1.510 & 22.00 & 5,08 & 2 & 10 & 0 & 0 & 5 & VAR & 0 & 0 & 0 & 0 & 0 & 2 & & 14 & 1394 & 1700 & 0 & 0 & 3774 & 0 & 0 & 3 & 2 & 1 & 4 \\
\hline BAHÇELIEVLER & 598.097 & 16.17 & $\% 4,04$ & 3 & \begin{tabular}{|l|}
13 \\
\end{tabular} & 1 & 0 & 5 & VAR & 0 & 0 & 0 & 0 & 0 & 2 & 1 & 11 & 1258 & 1734 & 306 & 0 & 4216 & 120 & 0 & 2 & 2 & 0 & 10 \\
\hline
\end{tabular}

(a)

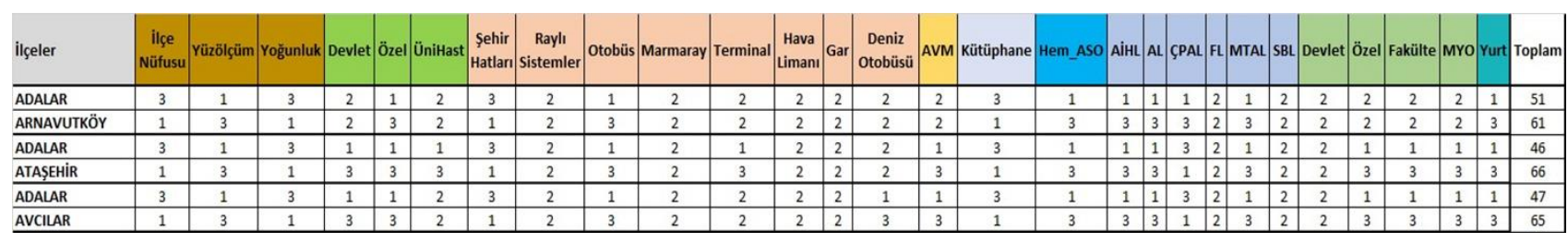

(b)

Şekil 6: Ölçüt puanlama sistemi (a) genel veri durumu, (b) karşılaştırma sonuç durumu

\subsubsection{Vektörel Harita Üretimi}

Yapılan uygulama sonucunda, elde edilen ilçe sıralamaları açık kaynak kodlu CBS yazılımında temsil edilmek üzere sayısallaştırılmıştır. Öncelikle internet aracılığıyla “.jpg” formatlı İstanbul ilçe haritası temin edilmiştir. İlk adımda temin edilen bu harita CBS projesinde altlık olarak kullanılması için “.tif” formatlı raster veri tipine dönüştürülmüştür. İkinci adımda ise elde edilen veriler ile doğru sonuçların elde edilmesi, sonuçların saklanması ve tekrar edilen verilerin önüne geçilebilmesi için veri tabanları oluşturulmuştur. Veritabanları ile üretilen veri depoları karar verme sürecinde önem teşkil etmektedir (Durduran \& Sarı, 2011). Bu sebeple, çalışmada pratik anlamda öznitelik bilgisi içeren bir veritabanı oluşturabilmek için açık kaynak kodlu Qgis yazılımı kullanılmışır. Bu yazılım ile "ilceler” isimli “.shp” uzantılı poligon vektör tipli katman oluşturularak, katmanın içerisine referans sağlaması için katman veri tabanına "ilce_ad", "ilce_sira", “ilce_averaj" ve "ilce_puan" isimli kolonlar eklenmiştir (Tablo 2). Bir sonraki adımda ise oluşturulan katman ile raster altlık harita üzerinde çizim yapılarak harita vektörel olarak sayısallaştırılmıştır.

Tablo 2: Özniteliklere ilişkin veri tabanı standartları

\begin{tabular}{lllll}
\hline Öznitelik Adı & İlce_sira & İlce_adi & İlce_averaj & İlce_puan \\
\hline Veri Tipi & Integer & String & Integer64 & Integer \\
Uzunluk & 3 & 25 & 7 & 4 \\
\hline
\end{tabular}

Öznitelik tablosunun oluşturulmasının ardından elektronik tabloda üretilen sonuçlar, yazılıma aktarılarak yazılımın içinde bulunan öznitelik verileriyle elektronik tablo verileri birleştirilmiştir. Bu işlemde iki tabloda da ortak kolon verilerine sahip ilce_sira ve sıra kolonları ilişkilendirilmiştir. Bu şekilde başlangıçta 4 adet kolona sahip öznitelik tablosuna 6 kolon daha ilave edilerek kolon sayısı 10'a çıkarılmıştır. Tablo 3’te öznitelik tablosuna ilişkin son durum gösterilmektedir. 


\begin{tabular}{|c|c|c|c|c|c|c|c|c|c|c|c|c|c|c|c|c|c|c|c|}
\hline Sıra & Takı & $\mathrm{KS}$ & $\mathbf{G}$ & 다 & $\mathrm{M}$ & AS & YS & AV & $\mathrm{P}$ & Sira & Tak & $\mathrm{KS}$ & $\mathbf{G}$ & B & $\mathbf{M}$ & AS & YS & AV & $\mathbf{P}$ \\
\hline 1 & FATін & 38 & 36 & 1 & 1 & 2569 & 1687 & 882 & 111 & 1 & FAтін & 38 & 36 & 1 & 12 & 2569 & 1687 & 882 & 111 \\
\hline 2 & & 38 & 36 & 1 & 1 & 456 & 1800 & 656 & 111 & 2 & & 38 & 36 & 1 & 12 & 2456 & 1800 & 656 & 111 \\
\hline 3 & ÜSK & 38 & 35 & 2 & 1 & 2520 & 1736 & 784 & 110 & 3 & & 38 & 35 & 2 & 12 & 2520 & 1736 & 784 & 110 \\
\hline 4 & ZEY & 38 & 32 & 2 & 4 & 2306 & 1950 & 356 & 104 & 4 & $Z E$ & 38 & 32 & 2 & 42 & 306 & 1950 & 56 & 104 \\
\hline 5 & BAHÇELIEVLER & 38 & 30 & 1 & 7 & 2290 & 1966 & 324 & 99 & 6 & & 38 & 30 & 1 & \begin{tabular}{l|l}
7 & 2 \\
\end{tabular} & 2290 & 1966 & 324 & 99 \\
\hline 6 & KÜÇi & 38 & 30 & 1 & 7 & 2281 & 1975 & 306 & 99 & 5 & & 38 & 30 & 1 & \begin{tabular}{l|l}
7 & 2 \\
\end{tabular} & 2281 & 1975 & 306 & 99 \\
\hline 7 & BEŞiK & 38 & 29 & 2 & 7 & 2251 & 2005 & 246 & 98 & 7 & BEYOĞLU & 38 & 29 & 2 & \begin{tabular}{l|l}
7 & 2 \\
\end{tabular} & 2274 & 1988 & 286 & 98 \\
\hline 8 & BEYC & 38 & 29 & 2 & 7 & 2274 & 1988 & 286 & 98 & 8 & BEŞ & 38 & 29 & 2 & \begin{tabular}{l|l}
72 \\
\end{tabular} & 2251 & 2005 & 246 & 98 \\
\hline 9 & Ş่işు் & 38 & 29 & 2 & 7 & 2243 & 2013 & 230 & 98 & 9 & Şiş & 38 & 29 & 2 & \begin{tabular}{l|l}
77 & 2 \\
\end{tabular} & 2243 & 2013 & 230 & 98 \\
\hline 10 & PEN & 38 & 28 & 1 & 9 & 2251 & 1995 & 256 & 95 & 10 & & 38 & 28 & 1 & \begin{tabular}{l|l}
9 & 2 \\
\end{tabular} & 2251 & 1995 & 256 & 95 \\
\hline 11 & SAF & 38 & 27 & 3 & 8 & 2223 & 2033 & 190 & 95 & 11 & & 38 & 27 & 3 & 82 & 2223 & 2033 & 190 & 95 \\
\hline 12 & BAK & 38 & 27 & 1 & 10 & 2221 & 2033 & 188 & 93 & 12 & BAF & 38 & 27 & 1 & 102 & 2221 & 2033 & 188 & 93 \\
\hline 13 & & 38 & 25 & 3 & 10 & 2251 & 2005 & 246 & 91 & 13 & & 38 & 25 & 3 & 102 & 2251 & 2005 & 246 & 91 \\
\hline 14 & A & 38 & 23 & 2 & 13 & 2210 & 2046 & 164 & 86 & 14 & & 38 & 23 & 2 & 132 & 10 & 2046 & 164 & 86 \\
\hline 15 & BEYKOZ & 38 & 22 & 4 & 12 & 2173 & 2083 & 90 & 86 & 15 & BEY & 38 & 22 & 4. & 122 & 2173 & 2083 & 90 & 86 \\
\hline 16 & $\mathrm{AV}$ & 38 & 19 & 4 & 15 & 2122 & 2129 & -7 & 80 & 16 & & 38 & 20 & 2 & 162 & 2190 & 2066 & 124 & 80 \\
\hline 17 & 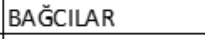 & 38 & 20 & 2 & 16 & 2190 & 2066 & 124 & 80 & 17 & & 38 & 19 & 4 . & 152 & 2122 & 2129 & -7 & 80 \\
\hline 18 & MAL & 38 & 19 & 3 & 16 & 2184 & 2015 & 169 & 79 & 18 & & 38 & 19 & 3 & 162 & 2184 & 2015 & 169 & 79 \\
\hline 19 & EYÜ & 38 & 17 & 6 & 15 & 2128 & 2128 & 0 & 78 & 19 & EYÜ & 38 & 17 & 6 & 152 & 2128 & 2128 & 0 & 78 \\
\hline 20 & BÜY & 38 & 18 & 1 & 19 & 2139 & 2117 & 22 & 75 & 20 & & 38 & 18 & 1 & 192 & 2139 & 2117 & 22 & 75 \\
\hline 21 & & 38 & 15 & 3 & 20 & & & & 71 & & & & 15 & 3 & 202 & & 2182 & & 71 \\
\hline 22 & ÜM & 38 & 16 & 1 & 21 & 2056 & 2194 & -138 & 71 & 22 & ÜM & 38 & 16 & 1 & 212 & 2056 & 2194 & -138 & 71 \\
\hline 23 & BAY & 38 & 14 & 3 & 21 & 2103 & 2163 & -60 & 69 & 23 & BA) & 38 & 14 & 3 & 212 & 2103 & 2163 & -60 & 69 \\
\hline 24 & KAC & 38 & 14 & 2 & 22 & 2054 & 2202 & -148 & 68 & 24 & & 38 & 14 & 2 & 222 & 2054 & 2202 & -148 & 68 \\
\hline 25 & GAZI & 38 & 14 & 1 & 23 & 2021 & 2235 & -214 & 67 & 25 & GA & 38 & 14 & 1 & 232 & 2021 & 2235 & -214 & 67 \\
\hline 26 & SEHIR & 38 & 12 & 4 & 22 & 2038 & 2218 & -180 & 66 & 26 & TUZ & 38 & 13 & 2 & \begin{tabular}{l|l}
23 & 2 \\
\end{tabular} & 2068 & 2188 & -120 & 66 \\
\hline 27 & ESEN & 38 & 13 & 2 & 23 & 1991 & 2133 & -142 & 66 & 27 & & 38 & 13 & 2 & 231 & 1991 & 2133 & -142 & 66 \\
\hline 28 & TUZ & 38 & 13 & 2 & 23 & 2068 & 2188 & -120 & 66 & 28 & & 38 & 12 & 4 & 222 & 2038 & 2218 & -180 & 66 \\
\hline 29 & ÇEK & 38 & 12 & 0 & 26 & 1975 & 2279 & -304 & 62 & 29 & KÖY & 38 & 12 & 0 & 26 & 1975 & 2279 & -304 & 62 \\
\hline 30 & ESEI & 38 & 9 & 2 & 27 & 1918 & 2338 & -420 & 58 & 30 & ESE & 38 & \begin{tabular}{|l|}
9 \\
\end{tabular} & 2 & 27 & 1918 & 2338 & -420 & 58 \\
\hline 31 & GÜ & 38 & 5 & 5 & 28 & 1951 & 2305 & -354 & 53 & 31 & GÜ & 38 & 5 & 5 & 28 & 1951 & 2305 & -354 & 53 \\
\hline 32 & ARNAVUTKÖ & 38 & 6 & 2 & 30 & 1915 & 2341 & -426 & 52 & 32 & SULTANGAZI & 38 & 5 & 4 & 29 & 1970 & 2294 & $-324 \mid$ & 52 \\
\hline 33 & SULTANGAZI & 38 & 5 & 4 & 29 & 1970 & 2294 & -324 & 52 & 33 & ARNAVUTKÖY & 38 & 6 & 2 & 30 & 1915 & 2341 & -426 & 52 \\
\hline 34 & ŞíLE & 38 & 5 & 3 & 30 & 1953 & 2303 & -350 & 51 & 34 & ŞiLE & 38 & 5 & 3 & 30. & 1953 & 2303 & -350 & 51 \\
\hline 35 & BEYL̇KDÜZÜ & 38 & 6 & 0 & 32 & 1954 & 2239 & -285 & 50 & 35 & BEYL̇KDÜZÜ & 38 & 6 & 0 & 32 & 1954 & 2239 & -285 & 50 \\
\hline 36 & SULTANBEYLI & 38 & 4 & 3 & 31 & 1967 & 2289 & -322 & 49 & 36 & SULTANBEYLI & 38 & 4 & 3 & 31 & 1967 & 2289 & -322 & 49 \\
\hline 37 & ÇATALCA & 38 & 2 & 3 & 33 & 1896 & 2360 & -464 & 45 & 37 & ÇATALCA & 38 & 2 & 3 & 33 & 1896 & 2360 & -464 & 45 \\
\hline 38 & SANCAKTEPE & 38 & 1 & 1 & 36 & 1865 & 2411 & -546 & 41 & 38 & SANCAKTEPE & 38 & 1 & 1 & 36 & 1865 & 2411 & -546 & 41 \\
\hline 39 & ADALAR & 38 & 1 & 0 & 37 & 1805 & 2444 & -639 & 40 & 39 & ADALAR & 38 & 1 & 0 & 37 & 1805 & 2444 & -639 & 40 \\
\hline
\end{tabular}

Şekil 7: Il/çe karşılaştırmalarının puanlama çıktısı ilk durum (solda), son durum (sağda)

Tablo 3: Özniteliklerin birleştirme durumu

\begin{tabular}{|c|c|c|c|c|c|}
\hline Kolon Bilgisi & Yazılım & & & & Elektronik Tablo \\
\hline $\begin{array}{l}\text { Öznitelik Adı } \\
\text { Veri Tipi } \\
\text { Uzunluk }\end{array}$ & $\begin{array}{l}\text { İlce_sira } \\
\text { İnteger } \\
3\end{array}$ & $\begin{array}{l}\text { İlce_adi } \\
\text { String } \\
25\end{array}$ & $\begin{array}{l}\text { İlce_averaj } \\
\text { İnteger64 } \\
7\end{array}$ & $\begin{array}{l}\text { İlce_puan } \\
\text { integer } \\
4\end{array}$ & $\begin{array}{lccccc}\text { KS } & \text { G } & \text { B } & \text { M } & \text { AS } & \text { YS } \\
\text { integer64 } & & & & \\
10 & & & & & \end{array}$ \\
\hline
\end{tabular}

Altlık harita üzerinde sayısallaştırılan ilçeler; öznitelik tablo birleştirmesinin ardından çalışmanın son adımı olan puanlama haritası işlemlerine başlanılmıştır. Çalışmada, Şekil 7'den yararlanılarak uygulamada oluşturulan ilçeler katmanına sıralama sütunu eklenmiş, ilçeler bu sütuna göre yeniden sıralanmış ve sıralama durumuna göre yüksek puan alan ilçeden düşük puan alan ilçeye doğru yeşil ile kırmızı renk skalası ile ilçeler gösterilerek, renklendirilmiş ilçe puan haritası oluşturulmuştur. Sonuç ürün olan 1/500000 ölçekli "renklendirilmiş ilçe puanlama haritası" kuzey işareti, ölçek ve lejant gibi haritanın temel unsurları eklenerek internet ortamında servis edilmek üzere hazır hale getirilmiştir (Şekil 8). 


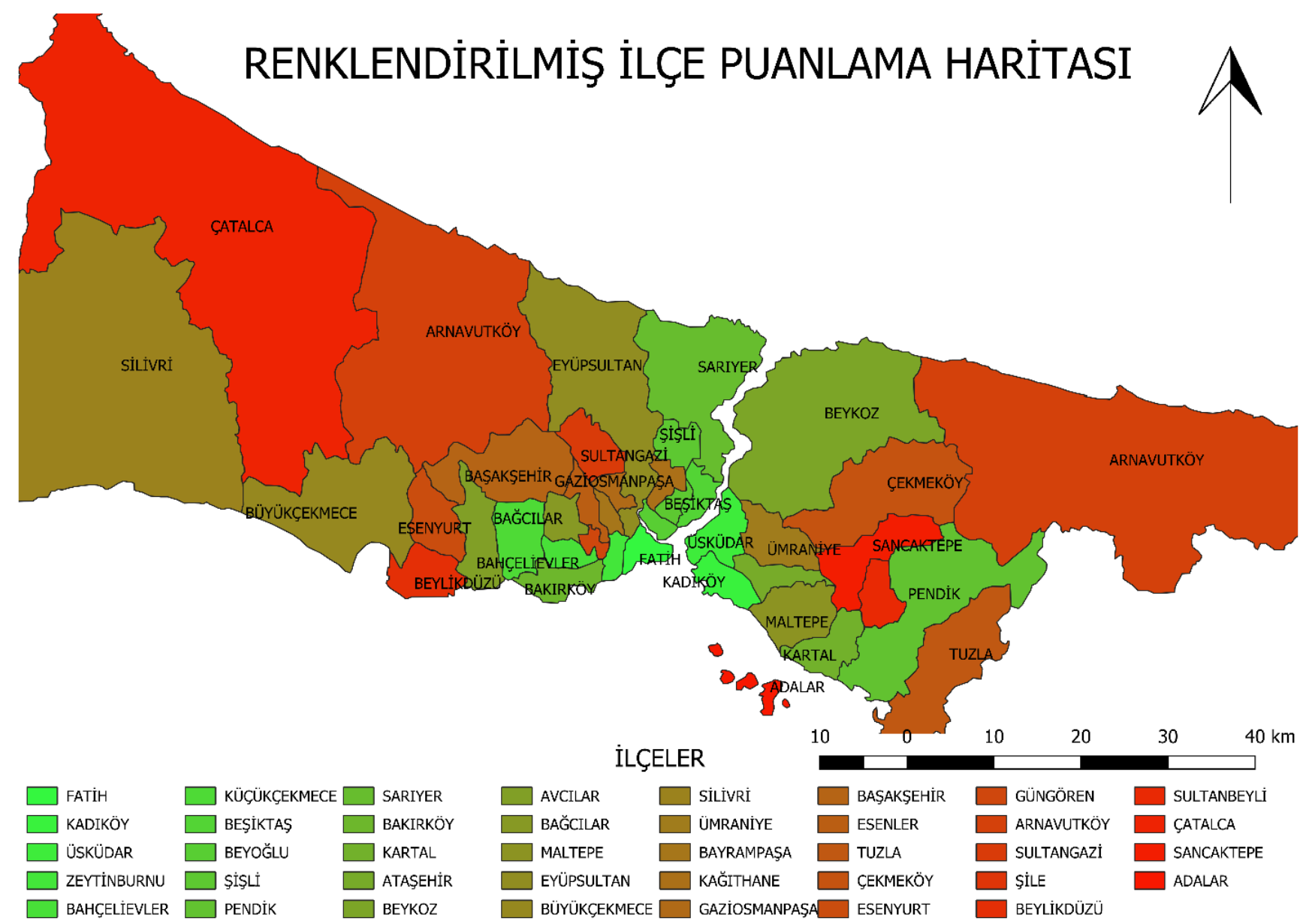

Şekil 8: Renklendirilmiş Il/çe puanlama haritası

\subsection{2 Çalışmanın Lokal Sunucuda Servis Edilmesi}

İnternet tabanlı haritalar masaüstü yazılımlardan bağımsız, yerel ağ bağlantısıyla kurum içinde ya da internet bağlantısının bulunduğu her yerden erişim sağlanabilen güvenli ve pratik sistemlerdir. Bu sistemler bilgisayar içinde yer alan veri deposunu işgal etmediği gibi ayrıca yazılım lisanslama ve güncelleme gibi işlemlere ihtiyaç duyulmadan, kullanıcılara hız ve ekonomik anlamda kolaylık sağlamaktadır. Ayrıca, sisteme tek bir merkezden müdahale edilebilmesi de oluşabilecek siber saldırı veya güvenlik açıklarının da önüne hızlı bir şekilde geçilmesini kolaylaştırmaktadır. Bu çalışmada üretilen renklendirilmiş vektörel puan haritasının internet ortamında servis edilmesi için açık kaynak kodlu ücretsiz bir CBS yazılımı kullanılmıştır. Yazılım içerisinde yer alan eklenti arayüzü kullanılarak; sınırlı veriler ile sınırsız sayıda seçenek sunumu ve harita sembolleri aracıllğıyla web tabanlı görsel harita üretilmiştir. Harita sembolleri, CBS'nin temel bir dil elemanı olarak coğrafi bilgiyi temsil eden ana görselleştirme aracıdır (Chen, He, Zhang \& Nover, 2016). Web kodlama eklentisi ile servis edilecek katmanlara ait bilgi kartlarının tasarımı yapılarak öznitelik bilgilerinin özet olarak gösterimi sağlanmıştır. İlçe sınırlarının içerisinde mesafe ölçme birimi metrik sistemde düzenlenmiş ve koordinat referans sisteminin eşleşmesi aktif hale getirilmiştir. Ayrıca, haritanın sayfada yer alan görüntüsünün, sayfa ekranını merkezinde ve sayfayı kaplayarak açılmasına dikkat edilerek, haritanın yakınlaştırma ve uzaklaştırma seviyeleri belirlenmiş, üretilen harita lokal olarak servis edilmiştir (Şekil 9). 


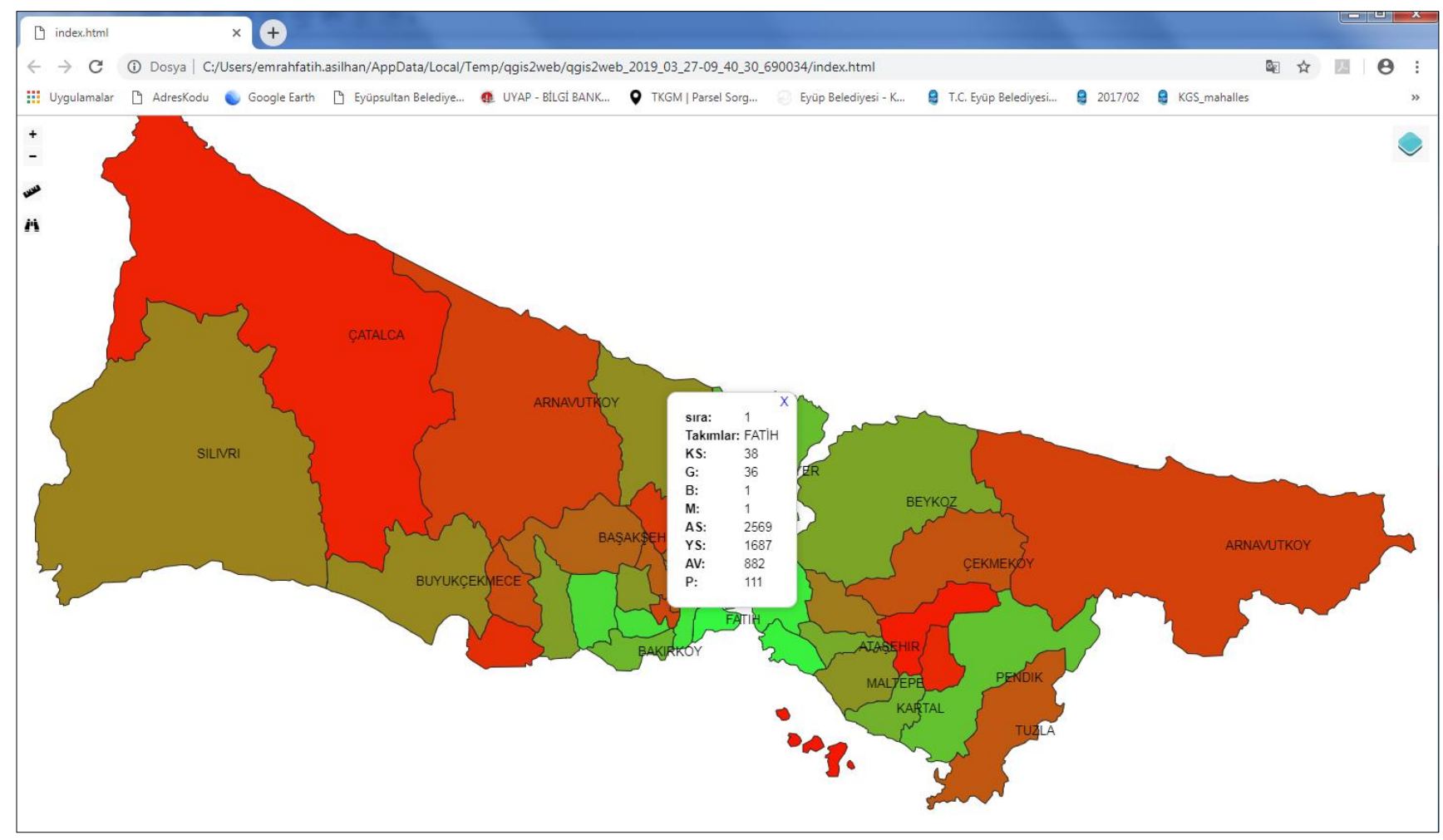

Şekil 9: Lokal olarak servis edilen internet sayfası görüntüsü

\section{Sonuç ve Öneriler}

CBS ile KDS'nin birbirleriyle ilişkilendirilerek kullanımı ile karar vericiler, karar verme süreçlerinde doğru seçim ve analiz sonuçlarına ulaşabilmektedirler. Müsabaka Yöntemi ile karar vericiler elinde bulunan sayısal verilerle ölçütlere müdahale etmeden bağımsız olarak sonuç elde edebilmektedir. Bu çalışmada, önerilen yöntem ile 39 ilçe için 28 ölçüte göre toplamda 20748 kez değerlendirme yapılmış; 741 adet ikili karşılaştırma sonucu elde edilmiştir. Gerçekleştirilen analizler ile İstanbul'da yer alan 39 ilçe, 28 ölçüt değerlendirmesi sonucu kazandığı puanlara göre sıralanmış, yer seçimi belirleme ve karar verme aşamasında hızlı ve doğru sonuçlar elde edilmiştir. Ayrıca, açık kaynak kodlu CBS yazılımında üretilen altlık harita üzerinde, mekan işaretlemesi yapılarak coğrafi bilgi içermeyen sayısal bilgiler somutlaştırılmıştır. Vektör veri tipli katman üzerinden oluşturulan öznitelik tablosu desteğiyle, karar analizi işlemlerinin veri tabanları ile daha hızlı yapıldı̆̆ gözlemlenmiştir. Şekil 10’da veri tabanı üzerinde yapılan sorgulama sonucunda puan cetveline göre ilk dört ve son dört sırada yer alan ilçeler sarı renk ile gösterilmektedir. Bu sonuçların yanı sıra, elektronik tabloların açık kaynak kodlu yazılım aracıyla vektör veri katmanı dosyasına bağlama işleminin yapılması sonucunda; 1134 adet meta verinin, katman veri tabanına pratik bir şekilde eklenmesi gerçekleştirilmiştir. Veri tabanında yer alan bilgilerle sıralama sonucuna uygun renklendirilmiş puan haritası üretilmiştir. Üretilen haritanın lokal sunucu üzerinden sorunsuz bir şekilde servisi yapılmıştır. Üretilen renklendirme haritaları sayesinde kullanıcılar tematik anlamda bölgeleri rahat bir şekilde ayırt edebilmektedir. Yöntem bu sayede, mevcut ya da planlanan sosyo-ekonomik gelişmeler, yatırım, sürdürülebilir çevre vb. projeler için kullanıcılara karar verme süreçlerinde; mekansal doğru verinin seçimine, mekansal güncel verinin özniteliklerini analiz edebilmeye ve kullanım amaçlarına yönelik tüm bilgileri sağlayarak pratik anlamda destek olmaya olanak sağlamaktadır. 


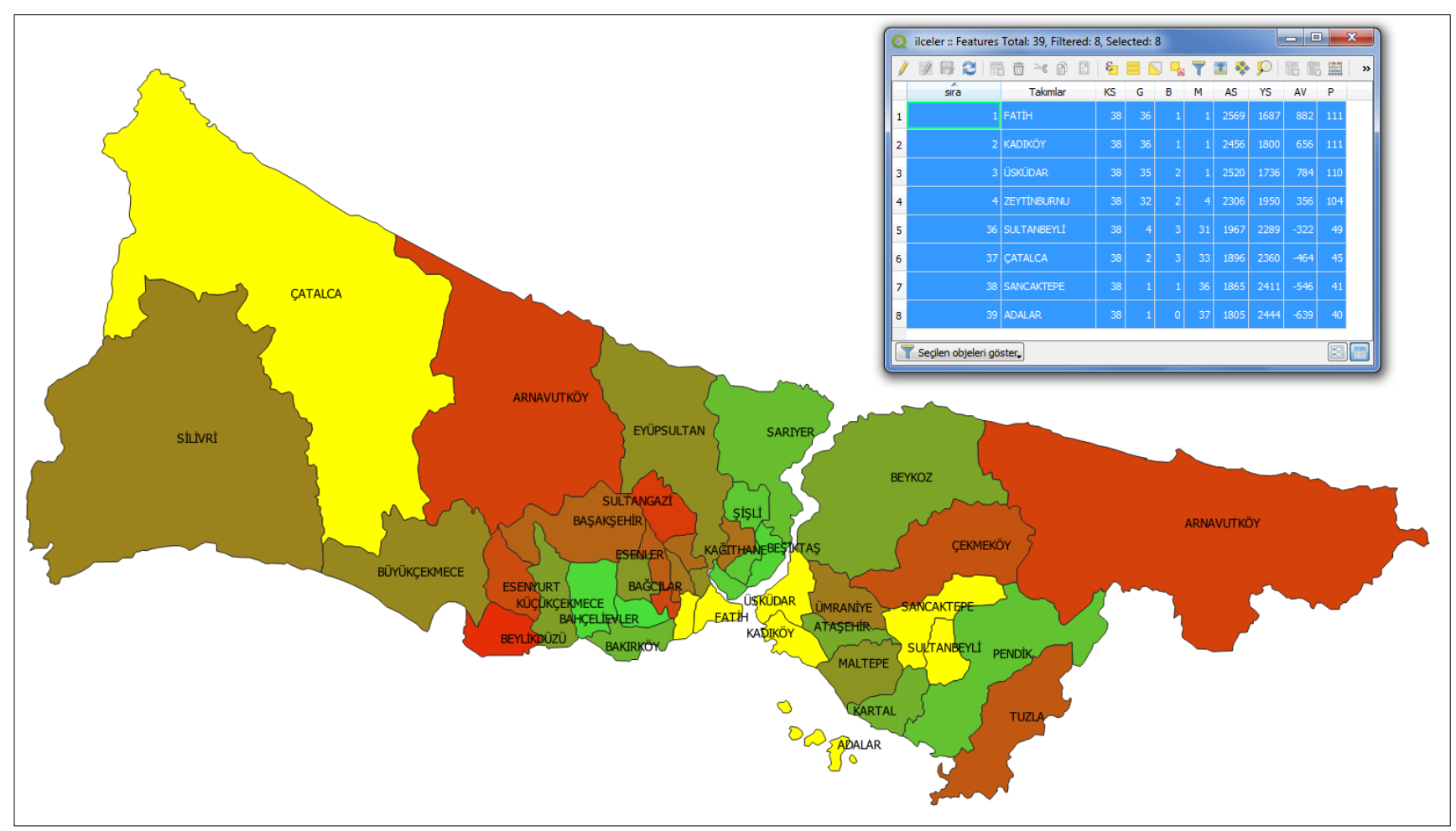

Şekil 10: Müsabaka yöntemi ile ilk 4 ve son 4 ilçenin sorgulama sonucu örnek gösterimi

Karar verme aşamasında kullanıcılar zaman zaman doğru sonuca, daha hızlı ulaşabilmek için destek sistemlerden yararlanmaktadır. Müsabaka Yöntemi kullanıcılara bu doğrultuda destek sağlayan pratik bir sistemdir. AHP, ELECTRE ve TOPSIS yöntemleri karar destek sistemi uygulamalarında karar vericiler tarafından yaygın olarak kullanılan yöntemlerdir. Geliştirilen Müsabaka Yöntemi; sistemin getirdiği kullanım kolaylı̆̆ı, pratik bir şekilde doğru veriye ulaşılabilme, görsel karar verme özelliği ve yeni ölçütlerin eklenerek farklı müsabakalarla genişletilebilir olması avantajları ile diğer yöntemlere alternatif olmaktadır. Ayrıca Müsabaka Yöntemi diğer yöntemlerden farklı olarak; anket sonuçlarına ve istatistiksel bilgilere gerek duymadan, odak gruplarından bağımsız, tüm ölçütlerin birbirleriyle olan bağlantılarını karşılaştırarak pratik olarak anlamlı sonuçlar elde etmek üzere tasarlanmıştır. Kullanıcılar, bu tasarım ile gerek excel üzerinde gerekse başka programlarda bu yöntemi kolaylıkla kullanılabilme imkanı bulmaktadırlar.

Bu çalışmada, önerilen Müsabaka Yöntemi’nin diğer yöntemlere alternatif olarak sunulmasını desteklemek amacıyla örnek veri uygulaması yapılmıştır. Bu aşamada, Avcılar, Arnavutköy ve Ataşehir ilçeleri rastgele olarak seçilmiş ve bu ilçelere ait yüzölçümü, hastane ve ulaşım verileri kullanılmıştır. Bu karşıllaştırma işleminde; her yöntem kendi algoritma yapısı ve sonuç formatına uygun olarak ele alınmıştır. Ayrıca, kullanılan ölçüt ağırlıkları eşit olarak alınmış; grup odakları ölçüt değerleri 1 olacak şekilde ön kabul yapılarak sonuçların yöntemlere göre objektif olarak değerlendirilmesi hedeflenmiştir. Bu dört yönteme göre yapılan karşılaştırma sonucunda Ataşehir birinci, Arnavutköy ikinci ve Adalar ise karar vericiye tercih edilmesi için önerilen üçüncü ilçe olmuştur (Tablo 4). Sonuçta minimum ölçüt değerleri ile gerçekleştirilen örnek karşılaştırmada Müsabaka Yöntemi’nin diğer yöntemlere göre veri girişi ve ön işleme adımları dikkate alındığında sonuca hızlı ulaşma, kullanıcıya tercih konusunda öneri sunma açısından daha uygun olduğu gözlenmiştir. 
Tablo 4: Müsabaka yöntemi ile diğer yöntemlerin karşılaştırılması

\begin{tabular}{llll}
\hline & ADALAR & ARNAVUTKÖY & ATAŞEHIR \\
\hline AHP & $3 .(\% 25)$ & $2 .(\% 32)$ & $1 .(\% 43)$ \\
ELECTRE & $3 .(0,0=0$ özellik) & $2 .(1,0=1$ özellik $)$ & $1 .(1,1=2$ özellik $)$ \\
TOPSİS & $3 .(0.6673)$ & $2 .(0.6698)$ & $1 .(0.7006)$ \\
MÜSABAKA YÖNTEMI & $3 .(2$ puan $)$ & $2 .(4$ puan $)$ & $1 .(6$ puan $)$ \\
GENEL TERCIH ÖNERISI & $\mathbf{3 .}$ & $\mathbf{2 .}$ & $\mathbf{1 .}$ \\
\hline
\end{tabular}

Sonuç olarak önerilen yaklaşım ile bilinen bu karar verme algoritmalarına alternatif bir kural geliştirilerek; CBS ile KDS'nin bütünleştirilmesi ile iki sistemle sonuca daha hızlı ulaşma hedefi gerçekleştirilmiştir. Böylece, son kullanıcılara çalışma sonuçlarının internet tabanlı harita aracılığıyla hızlı bir şekilde servis edilmesi sağlanmıştır. Müsabaka Yöntemi ile geliştirilen algoritma yardımıyla kullanıcılar elektronik tablolarda yer alan veri envanterlerini ikili karşılaştırmalar yaparak seçim konusunda fikir elde edebilmektedir. Ayrıca elektronik tablolar, öznitelik tablosu şeklinde CBS sistemleri ile desteklendiği takdirde tekrarlı verilerin önüne geçilerek analiz, değerlendirme ve mekansal yer belirleme işlemleri daha kolay olacaktır. Yöntemin basit bir düzenek ile tasarlanmış olması pratik anlamda çözüm sağladığı gibi üst düzey programlarla yöntemin desteklenmesi halinde yöntem ile daha anlamlı sonuçlar elde edilebilecektir. Ayrıca yöntem coğrafi bilgi içermeyen elektronik tabloların CBS çalışmalarında da değerlendirilebilmesine olanak sağlamaktadır. Bu sayede birbirinden bağımsız sistemler olan KDS ile CBS'nin birbirleri ile bütünleştirilerek kullanılması halinde alınacak kararlar daha anlamlı olacaktır.

\section{Kaynaklar}

Anbaroğlu, B. (2017). Gönüllü Coğrafi Bilgi: Mekânsal Bilişim Çalışmalarına Web 2.0 Devrinde Yeni Bir Yaklaşım. Harita Dergisi, 158, $1-9$.

Arslan, V., \& Yılmaz, G. (2010). Karar destek sistemlerinin kullanimi için uygun bir model geliştirilmesi. Journal of Aeronautics and Space Technologies, 4(4), 75-82.

Aydın, G., \& Erdoğan, A. (2011). Web tabanlı bir mekânsal karar destek sistemi tasarımı ve geliştirilmesi. Elektrik-Elektroik-Bilgisayar Sетроzуити.

Chen, W., He, B., Zhang, L., \& Nover, D. (2016). Developing an integrated 2D and 3D WebGIS-based platform for effective landslide hazard management. International Journal of Disaster Risk Reduction, 20, 26-38.

Coutinho-Rodrigues, J., Simão, A., \& Antunes, C. H. (2011). A GIS-based multicriteria spatial decision support system for planning urban infrastructures. Decision Support Systems, 51(3), 720-726.

Demireli, E. (2010). TOPSIS çok kriterli karar verme sistemi: Türkiye'deki kamu bankaları üzerine bir uygulama. Girişimcilik ve Kalkınma Dergisi 5(1), 101-112.

Durduran, S. S., \& Sarı, F. (2011). Konya ilinde meydana gelen bisiklet kazalarinin karar destek sistemleri yardimiyla web tabanli mekânsal analizi. Selçuk Üniversitesi Mühendislik, Bilim ve Teknoloji Dergisi, 26(1), 23-32.

Erden, T., \& Coşkun, M. Z. (2011). Coğrafi bilgi sistemleri ve analitik hiyerarşi yöntemi yardimiyla itfaiye istasyon yer seçimi. $T M M O B$ Karita ve Kadastro Mühendisleri Odası 13. Türkiye Bilimsel ve Teknik Kurultayl, 301.

González, A., Donnelly, A., Jones, M., Chrysoulakis, N., \& Lopes, M. (2013). A decision-support system for sustainable urban metabolism in Europe. Environmental Impact Assessment Review, 38, 109-119.

Grossman, T. A., Mehrotra, V., \& Özlük, Ö. (2007). Lessons from mission-critical spreadsheets. Communications of the Association for Information Systems, 20(1), 60.

İrfan, M., Koj, A., Sedighi, M., \& Thomas, H. (2017). Design and development of a generic spatial decision support system, based on artificial intelligence and multicriteria decision analysis. GeoResJ, 14, 47-58.

Karacasu, M. (2007). Kentiçi Toplu Taşıma Yatırımlarının Değerlendirilmesinde Karar Destek Modeli (ELECTRE Yöntemi) Kullanımı. Ulaştırma Kongresi, 155-164.

Laudon, K. C., \& Laudon, J. P. (2006). Management information system. Pearson Education. 
Malczewski, J. (1999). GIS and multicriteria decision analysis. John Wiley \& Sons.

Ömürbek, N., \& Şimşek, A. (2014). Analitik hiyerarşi süreci ve analitik ağ süreci yöntemleri ile online alişveriş site seçimi. Yönetim ve Ekonomi Araştırmaları Dergisi, 12(22), 306-327.

Santos, L., Coutinho-Rodrigues, J., \& Antunes, C. H. (2011). A web spatial decision support system for vehicle routing using Google Maps. Decision Support Systems, 51(1), 1-9.

Taşbaş S., Karadağ., \& Kösemli M., (2015). Spatial decision support system for urban renewal. Yönetim Bilişim Sistemleri Dergisi, 1(1). 50-63.

Uyan, M., Çay, T., \& Akçakaya, O. (2013). A spatial decision support system design for land reallocation: a case study in turkey. Computers and Electronics in Agriculture, 98, 8-16.

Yao, X., Zhu, D., Yun, W., Peng, F., \& Li, L. (2017). A WebGIS-based decision support system for locust prevention and control in China. Computers and Electronics in Agriculture, 140, 148-158.

URL-1: https://istanbulharitasi360.com/istanbul-ilce-haritasi\#.XJpLH1UzZhE, (Erişim Tarihi: 16 Nisan 2019). 